\title{
EFFECT OF TAXIWAY EXTENSION ON RUNWAY CAPACITY AT LJUBLJANA - JOŽE PUČNIK AIRPORT
}

\author{
Andrej Grebenšek ${ }^{\mathbf{1}}$, Tadej Kosel ${ }^{\mathbf{2}}$ \\ ${ }^{1,2}$ University of Ljubljana, Faculty of Mechanical Engineering, Slovenia
}

Received 2 January 2014; accepted 22 April 2014

\begin{abstract}
This paper looks at the effect of the taxiway extension on runway capacity at Ljubljana - Jože Pučnik Airport, which serves as the main airport of the Republic of Slovenia. Due to it's geographical location instrument arrivals are only possible from south-east, on the runway 30 . This situation severely reduced the capacity of the airport until in 2007, taxiway A was extended fully to the threshold of the runway 30. Main part of the paper scrutinizes different scenarios of air traffic on the runway, including departures only, arrivals only and mixed operations, based on real time approximation of the traffic mix. Aim of the research is to provide comparison in runway capacity before and after the taxiway A extension.
\end{abstract}

Keywords: airport, taxiway extension, runway capacity, take-off, landing.

\section{Introduction}

Ljubljana - Jože Pučnik Airport is the main airport of the Republic of Slovenia. Its catchment area of passengers extends as well across the national borders in particular to the South Carinthia in Austria on one side and to the Triest and its hinterland on the other side. With almost 1,7 million passengers per year in 2008 (1,2 million passengers at present) (Aerodrom Ljubljana, 2014), it represents a medium size regional airport, serving as a feeder airport for major European hubs.

Due to the fact that the Ljubljana - Jože Pučnik Airport was initially intended to be a military airport, which would potentially serve as the first defense line of the western borders of the former Yugoslavia, it was relatively inconveniently placed at the foot of the Karavanke Mountains. Due to the high terrain to the north and northwest, instrument air traffic patterns are mainly limited to the south and southeast of the airport. This fact extremely limits the air traffic management (ATM) capacity of the airport. In order to utilize the available capacity in full, proper ground infrastructure of the airport is therefore essential.

This paper looks at the theoretical runway capacity of the airport based on the old infrastructure (taxiway A built only halfway along the runway), which was the case from the opening of the airport until 2007 and compares it to the current state of the ground infrastructure, with the taxiway A extended all the way, along the full length of the runway.

\section{Defining the Problem}

Air traffic growth in Europe is steady, despite of different unpredictable events (military conflicts in the surrounding countries, natural catastrophes, etc.) or economic crisis. On average traffic grew by around 7\% per year (Eurocontrol, 2013)

${ }^{1}$ Corresponding author: andrej.grebensek@me.com

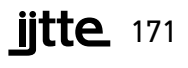


until 2008 and is expected to grow by average 2,5\% since then until 2020.

Airports are becoming more and more a severe capacity-limiting factor, since they represent a point (place on the Earth), where all air traffic is converging to, or diverging from (Kumar and Sherry, 2009; Šimecki et al., 2013). On average, in Europe, airports contribute to around $17 \%$ of all air traffic delays.

It is not possible to simply build another airport, when the first one is saturated with traffic. Main limiting factors are as follows:

- catchment area of potential passengers and cargo,

- proximity of another airport due to potential interference of air traffic patterns,

- availability of suitable building ground,

- obstacle and high terrain limitations,

- extremely high cost of the infrastructure and equipment,

- cost efficiency of the operations from that airport, etc.

Primary goal of any airport management structures is therefore to utilize and upgrade the existing airport infrastructure to its maximum (Mota and Boosten, 2013). In order to be able to do that it is essential for them to know what they have available, what is the existing capacity of the airport (mainly linked to the runway(s) capacity) and what is the potential of the upgrade.

An example of how runway capacity for different type of operations can be determined is shown in the remaining part of this paper.

\section{Capacity Calculations}

\subsection{Essential Data for Calculations}

In order to as much as possible define a realistic scenario, air traffic patterns with all relevant attributes need to be recorded. For the purpose of this study only instrument (IFR - Instrument Flight Rules) traffic will be considered, despite of the fact that air traffic at the Ljubljana - Jože Pučnik Airport consist of both, instrument and visual (VFR Visual Flight Rules) traffic. This is due to the fact that only IFR traffic, due to its rigidness, represents a limiting factor for the runway capacity. VFR traffic is flexible enough and can be squeezed in between the IFR arrivals and departures in such a way that it would only contribute to the overall runway capacity.

Since the composition of traffic and traffic patterns at the Ljubljana - Jože Pučnik Airport did not change significantly over the years and also to allow more objective comparison of the results, similar or even the same data as in Grebenšek and Pavlin (2004) are used for calculations.

Composition of the traffic is presented in Table 1. Three categories of aircraft are represented at the airport:

- category $A$, jet aircraft, for example Airbus 320 (A-320), Boeing 737 (B737), Canadair Regional Jet (CRJ),

- category B, turbo-prop aircraft, for example ATR 42 or ATR 72, Turbolet (L-410), de Havilland Canada Dash 7 or 8 (DHC-7/8), 
- category C, propeller aircraft, for example Piper Arrow (PARO), Piper Seneca (PA-34), Cessna 172 or 182 (C$172 / 182)$.

Majority of the operations are done by the national carrier Adria Airways and few foreign air carriers, therefore it can be presumed that around $70 \%$ of the operations at the airport is done by the aircraft category A. Around $20 \%$ of the operations is done by the aircraft category $B$, used as passengers aircraft by the foreign air carriers or as cargo aircraft mainly for postal service. The rest $10 \%$ of operations is performed by the aircraft category C, which are either private IFR flights or IFR training flights.

Table 1

Composition of Traffic

\begin{tabular}{|c|c|c|c|c|}
\hline Aircraft category & $\begin{array}{c}\text { Landing speed } \\
{[\text { Kts] }}\end{array}$ & $\begin{array}{c}\text { Runway } \\
\text { occupancy }[\mathbf{s}]\end{array}$ & Arrivals [\%] & Departures [\%] \\
\hline A & 135 & 50 & 70 & 70 \\
\hline B & 110 & 40 & 20 & 20 \\
\hline C & 90 & 30 & 10 & 10 \\
\hline
\end{tabular}

Due to the fact that Ljubljana - Jože Pučnik Airport is not an airport where aircraft would remain parked for a longer period of time (with some minor exceptions, when aircraft fly in for maintenance purposes only) it is also safe to assume that the percentage of arriving aircraft equals the percentage of $\Delta T_{i j}=\frac{d_{i j} 3600}{v_{j}}$ and

$\Delta T_{i j}=\frac{d_{i j} 3600}{v_{i}}+l\left(\frac{1}{v_{j}}-\frac{1}{v_{i}}\right) 3600$ departing aircraft, and vice versa.

\subsection{The Method for Calculations}

Runway capacity calculations are performed on the basis of different scenarios. First scenario includes arrivals only, second one departures only and third one mixed operations. At the end ultimate runway capacity is evaluated, based on the real time mix of the above scenarios.

Calculations of the runway capacity are done with the help of the principles and equations, described in full in Horonjeff et al. (2010).

\subsubsection{Arrivals Only}

Capacity for arrivals only is calculated with the following equations (Eq. (1) and Eq. (2)):

Where:

- $\Delta T_{i j}$ is time between arrivals,

- $d_{i j}$ is distance between the two succeeding aircraft,

- $l$ is distance of the arrival path,

- $v_{i}$ is speed of the leading aircraft,

- $v_{j}$ is speed of the trailing aircraft.

Eqs. (1) and (2) are used for calculation of the matrix $\left[M_{i j}\right]$ of minimum separation times between arrivals $\left(m_{i j}\right)$. Eq. (1) is used if leading and trailing aircraft travel at the same approach speed or if the leading aircraft is slower than the trailing aircraft. If the leading aircraft is faster than the trailing aircraft, then Eq. (2) is used.

Based upon the data from Table 1, a matrix $\left[P_{i j}\right]$ of probabilities of sequences 
of operations is calculated. Lastly a matrix $\left[B_{i j}\right]$ of buffer times $\left(b_{i j}\right)$ is calculated. Using the air traffic control operational experience (where separations between aircraft are never mathematically precise) an assumption is made that the standard deviation $\sigma_{0}$ equals $20 \mathrm{~s}$ (roughly $0,5 \mathrm{NM}$ ) and that the probability of the mistake is $10 \%$, meaning that $q_{v}$ (the number of standard deviations from the mean in which a certain percentage of the area under the normal curve would be found) equals 1,28 . For the calculation of $b_{i j}$ following equations (Eq. (3) and Eq. (4)) are used with the same logic as with Eqs. (1) and (2):

$b_{i j}=q_{v} \sigma_{0}$

and

$b_{i j}=q_{v} \sigma_{0}-d_{i j}\left(\frac{1}{v_{j}}-\frac{1}{v_{i}}\right)$

Expected time between arrivals $\left(\boldsymbol{E}\left(\Delta \boldsymbol{T}_{i j}\right)\right)$ is then calculated with the help of the following Eq. (5):

$E\left(\Delta T_{i j}\right)=\Sigma\left[P_{i j}\right]\left[M_{i j}+B_{i j}\right]$

Finally runway capacity for arrivals only $\left(C_{a}\right)$ is calculated with the help of the following Eq. (6):

$C_{a}=\frac{3600}{E\left(\Delta T_{i j}\right)}$

\subsubsection{Departures Only}

The expected time between the departures $\left(\boldsymbol{E}\left(\boldsymbol{t}_{\boldsymbol{d}}\right)\right)$ is calculated with the following Eq. (7):

$$
E\left(t_{d}\right)=\Sigma\left[P_{i j}\right]\left[t_{d}\right]
$$

Where $\left[\boldsymbol{t}_{\boldsymbol{d}}\right]$ is the matrix of separation times $\left(\boldsymbol{t}_{\boldsymbol{d}}\right)$ between departures taking into account full mix of different aircraft categories.

Lastly the runway capacity for departures only $\left(C_{d}\right)$ is calculated with the help of the following Eq. (8):

$C_{d}=\frac{3600}{E\left(t_{d}\right)}$

\subsubsection{Mixed Operations}

The model for runway capacity calculations is based on the following operating rules:

- arrivals have priority over departures,

- only one aircraft can occupy the runway at one time,

- departure cannot be released if the subsequent arrival is less than 2 nautical miles (NM) from the runway threshold,

- $\quad$ successive departures are spaced at a minimum time separation equal to the departure service time.

Expected required time between the arrivals $\boldsymbol{E}\left(\Delta \boldsymbol{T}_{\boldsymbol{i j}}\right)$ to release certain number of departures $\left(n_{d}\right)$ is calculated with the help of the following Eq. (9):

$E\left(\Delta T_{i j}\right) \geq E\left(R_{i}\right)+E\left(\frac{\delta_{d}}{v_{j}}\right)+E\left(B_{i j}\right)+\left(n_{d}-1\right) E\left(T_{d}\right)$

Where:

- $\quad \boldsymbol{E}\left(\boldsymbol{R}_{\boldsymbol{i}}\right)$ is expected runway occupancy time,

$\boldsymbol{E}\left(\frac{\boldsymbol{\delta}_{\boldsymbol{d}}}{v_{j}}\right)$ is expected minimum distance
time,

- $\quad \boldsymbol{E}\left(\boldsymbol{B}_{\boldsymbol{i j}}\right)$ is expected interval buffer time,

- $\boldsymbol{n}_{\boldsymbol{d}}$ is number of departures. 
After the evaluation of the time gap needed to release one, two or more departures between the two arrivals, respective times are compared to the $\left[M_{i j}\right]$ times. Out of $\left[P_{i j}\right]$ probability $\left(\boldsymbol{p}_{n d}\right)$ on what is the chance to release on departure between two arrivals or to release two departures between two arrivals etc. is evaluated.

$$
C_{m}=\frac{3600}{E\left(T_{d}\right)}\left(1+\Sigma n_{d} p_{n d}\right)
$$

\subsection{Taxiway A Partially Existing}

The situation when taxiway A was only partially built existed from the opening of the Ljubljana - Jože Pučnik Airport (previously known as Ljubljana - Brnik Airport) in 1963

Finally runway capacity for mixed operations $\left(\boldsymbol{C}_{\boldsymbol{m}}\right)$ is calculated as follows (Eq. (10)): until 2007. Layout of the Airport runway with associated taxiways is presented on Fig. 1.

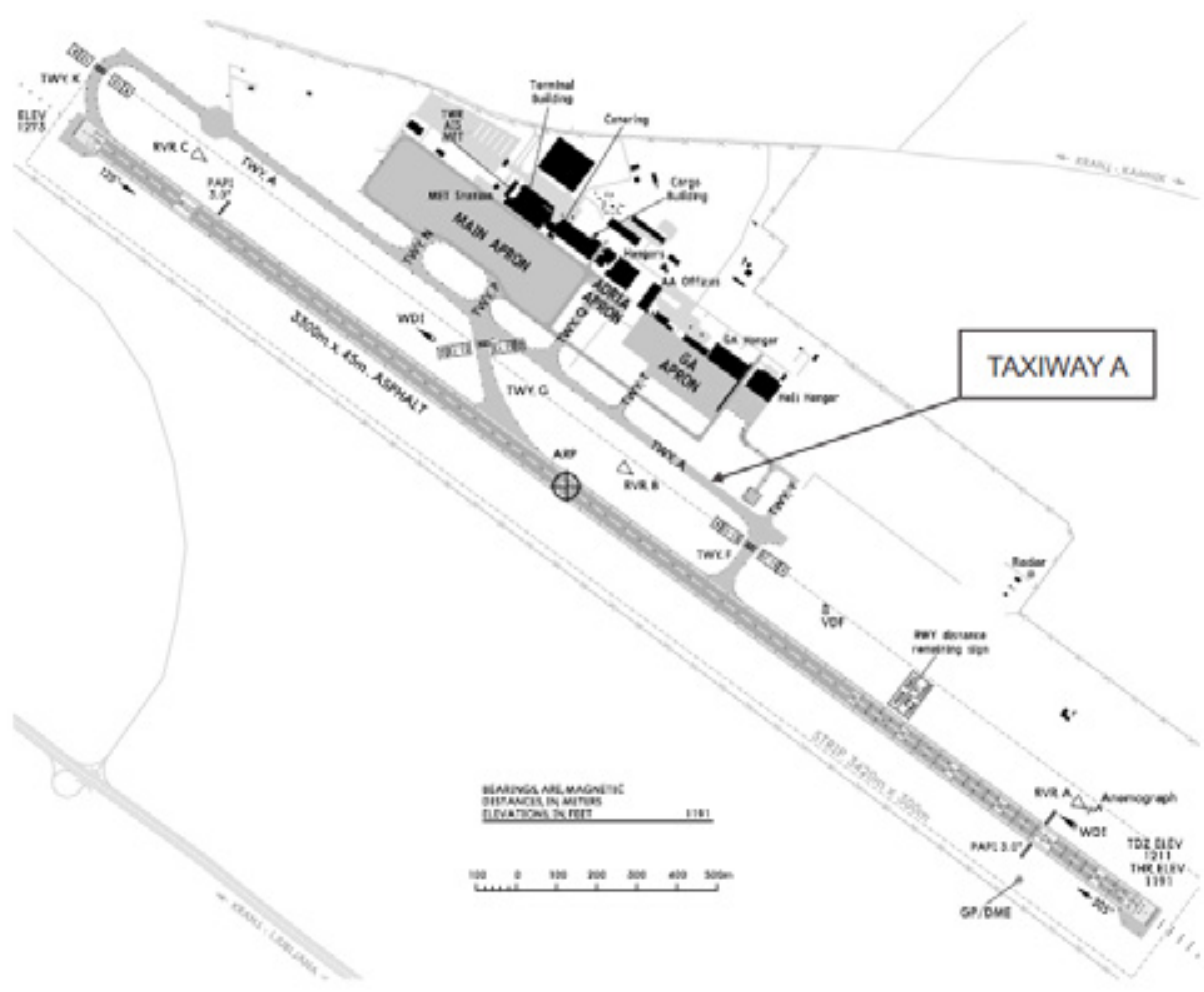

Fig. 1.

Airport Runway and Taxiways Layout Until 2007

Source: Grebenšek and Pavlin (2004) 
Aircraft generally landed on runway 31, which was and still is the only available runway for instrument (IFR) landings. Due to constant change of Earth's magnetic field, this runway was in 2012 renamed into runway 30 , this being more appropriate for the current runway orientation in relation to the magnetic north. Take-offs were executed in both directions 31 (30) and 13 (12), which are considered in calculations.

Composition of traffic is presented in Table 1.

As a base scenario it is assumed that takeoffs and landings were executed in the same direction on the runway 31 . Such traffic pattern is, especially in peak hours less complicated for an Air Traffic Control Officer and by all means the safest.
In quieter periods of the day traffic landed on the runway 31 and departed from the runway 13.

Despite of the fact that taxiway A was extended to the intersection $\mathrm{F}$, all categories of aircraft were still not able to use it, due to it's technical limitations.

Category A aircraft therefore needed to execute backtrack in case of take-off from the runway 31. Average measured time spent for that was $180 \mathrm{~s}$. Categories B and C aircraft, could take-off from the runway 31 , without executing any backtrack.

Rules for aircraft separation are presented in Table 2.

Table 2

Rules for Aircraft Separation

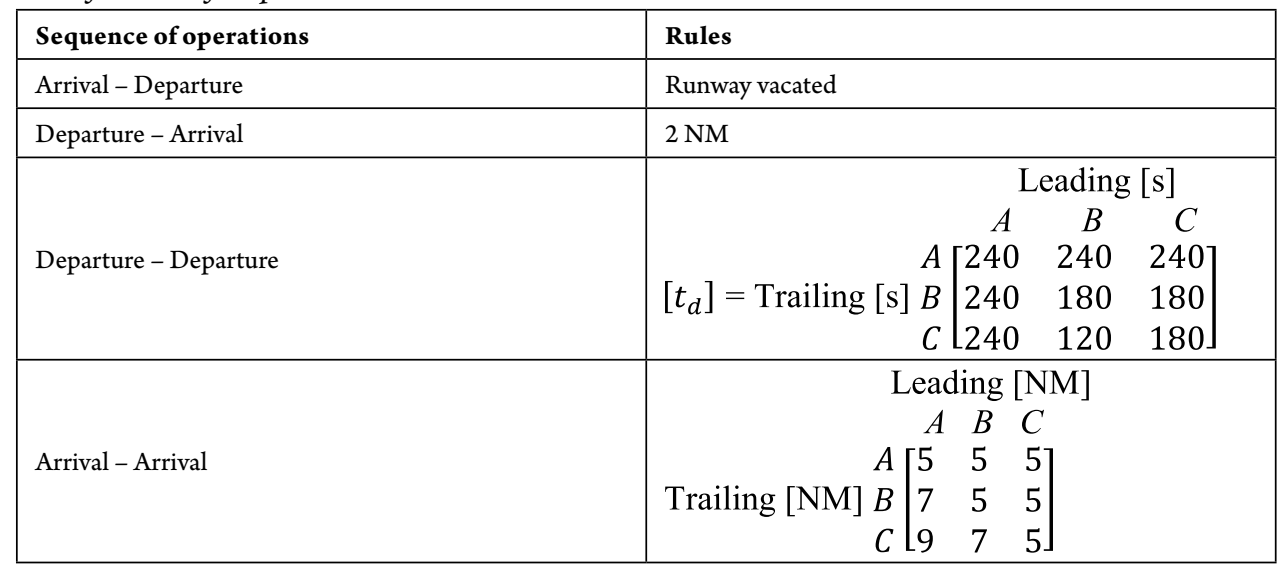


3.3.1. Capacity Calculation for Arrivals only on Runway 31

Based on Eqs. (1) and (2) $M_{i j}$ was calculated:

\begin{tabular}{|c|c|c|c|}
\hline & & ading & \\
\hline & A & $B$ & $C$ \\
\hline & $A[134$ & 134 & 134 \\
\hline Trailing [s] $B$ & \begin{tabular}{l|l}
$B$ & 251
\end{tabular} & 164 & 164 \\
\hline & $C[380$ & 306 & 200 \\
\hline
\end{tabular}

Then $P_{i j}$ was calculated, based on the data from Table 1:

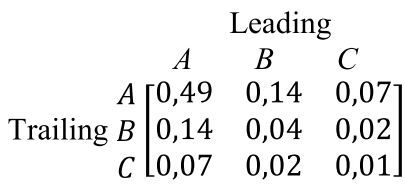

Finally based on Eqs. (3) and (4) $B_{i j}$ was calculated:

\begin{tabular}{|c|c|c|c|}
\hline & & ding & \\
\hline & $A$ & $B$ & $C$ \\
\hline & $4[26$ & 26 & $26]$ \\
\hline Trailing [s] $B$ & 0 & 26 & 26 \\
\hline$C$ & {$[0$} & 0 & $26]$ \\
\hline
\end{tabular}

With the help of Eqs. (5) and (6) runway capacity for arrivals only $\left(\boldsymbol{C}_{\boldsymbol{a}}\right)$, was calculated at 19 operations per hour.

\subsubsection{Capacity Calculation for Departures only from Runway 31}

With the help of data $\left[t_{d}\right]$ from Table 2 and Eqs. (7) and (8), runway capacity for departures only $\left(\boldsymbol{C}_{d}\right)$, was calculated at 16 operations per hour.

\subsubsection{Capacity Calculation for Mixed Operations on Runway 31}

$\boldsymbol{E}\left(\Delta \boldsymbol{T}_{i j}\right)$ was calculated using the Eq. (9). Data from Table 1 was used for calculation of $\boldsymbol{E}\left(\boldsymbol{R}_{\boldsymbol{i}}\right)$ as well as data from Tables 1 and 2 were used for calculation of $\boldsymbol{E}\left(\frac{\delta_{d}}{p_{i}}\right)$. Finally data from $\boldsymbol{P}_{i j}$ and $\boldsymbol{B}_{i j}$ were used for calculation of $\boldsymbol{E}\left(\boldsymbol{B}_{i j}\right)$. Results showed that $125 \mathrm{~s}$ is needed to release one departure between the two arrivals, $359 \mathrm{~s}$ is needed to release two departures between the two arrivals and $593 \mathrm{~s}$ is needed to release three departures between the two arrivals.

By observing $\left[M_{i j}\right]$ it was concluded that $p_{n d}$ to release one departure between the two arrivals is $0,3(30 \%)$, to release two departures between the two arrivals is 0,07 (7\%) and to release three departures between the two arrivals is 0 .

With the help of Eq. (10) runway capacity for mixed operations $\left(C_{m}\right)$, was calculated at 23 operations per hour.

\subsubsection{Ultimate Capacity Calculation for Runway 31}

Observations of traffic at Ljubljana - Jože Pučnik Airport showed that it is safe to assume that in one hour, one third of the time aircraft only depart, one third of the time aircraft only arrive and one third of the time mixed operations are performed.

Ultimate capacity $\left(C_{r}\right)$ was calculated with the help of the following Eq. (11):

$C_{r}=\Sigma x C_{x}$

Where:

- $x$ is a share of particular type of operations in one hour,

$-C_{x}$ is runway capacity of particular type of
operations. Ultimate runway capacity for runway $31\left(C_{r}\right)$, was calculated at 20 operations per hour. 


\subsubsection{Capacity Calculation for Departures only from Runway 13}

Due to the fact that aircraft category A do not need to backtrack the runway in case of departure from runway 13 , the matrix of separation times $\left[t_{d}\right]$ in Table 2 can be modified as follows:

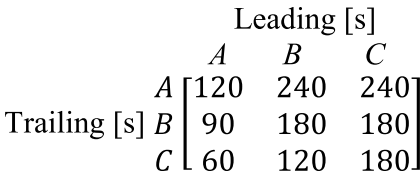

With the help of data $\left[t_{d}\right]$ above and Eqs. (7) and (8), runway capacity for departures only runway $13\left(C_{d}\right)$, was calculated at 26 operations per hour.

\subsubsection{Capacity Calculation for Mixed Operations Runways 31 and 13}

For mixed operations, when aircraft land on runway 31 and depart from runway 13, different separation minima as stated in Table $2(2 \mathrm{NM})$ is required. Departing aircraft must overfly whole length of the runway $(1,8 \mathrm{NM})$, climb as far as navigational aid MG (4,2 NM) to avoid high terrain and move away from the arrival path of the arriving aircraft by at least $5 \mathrm{NM}$, before the arriving aircraft can be cleared for final approach. Whole departure path sums up to $11 \mathrm{NM}$, whereas the arrival path lasts 10,5 NM.

Data of recalculation of these distances into times needed to overfly them, including the time for the arriving aircraft to vacate the runway via taxiway $\mathrm{G}$ are presented in the matrix of the arrival - departure cycles $\left[t_{d a}\right]$ :

\begin{tabular}{|c|c|c|c|}
\hline & & rrival & \\
\hline & $A$ & $B$ & $C$ \\
\hline & $A[530$ & 580 & 650 \\
\hline Departure $[\mathrm{s}] B$ & $\begin{array}{ll}B & 600\end{array}$ & 650 & 720 \\
\hline$C$ & $c\lfloor 730$ & 780 & 850 \\
\hline
\end{tabular}

The expected time for arrival - departure cycle $\boldsymbol{E}\left(\boldsymbol{t}_{\boldsymbol{d a}}\right)$ is calculated with the help of the following Eq. (12):

$E\left(t_{d a}\right)=\Sigma\left[P_{i j}\right]\left[t_{d a}\right]$

With the help of Eq. (10) runway capacity for mixed operations runways 31 and $13\left(C_{m}\right)$, was calculated at 13 operations per hour.

\subsubsection{Ultimate Capacity Calculation for Arrivals on the Runway 31 and Departures from the Runway 13}

Using the same assumptions with regards to the share of operations in one hour as in 2.3.3 and with the help of Eq. (11), ultimate runway capacity for arrivals on the runway 31 and departures from runway $13\left(C_{r}\right)$, was calculated at 20 operations per hour.

\subsection{Taxiway A Extended Along the Full Length of the Runway}

As a response to steady growth in air traffic (peak of airport operations was recorded in 2008), managers of the Ljubljana - Jože Pučnik Airport in 2007 decided to extend the taxiway A along the full length of the runway. Current layout of the runway with associated taxiways is presented in Fig. 2. As already described in 2.3, runway orientation was in 2012 renamed from 3113 into $30-12$. 


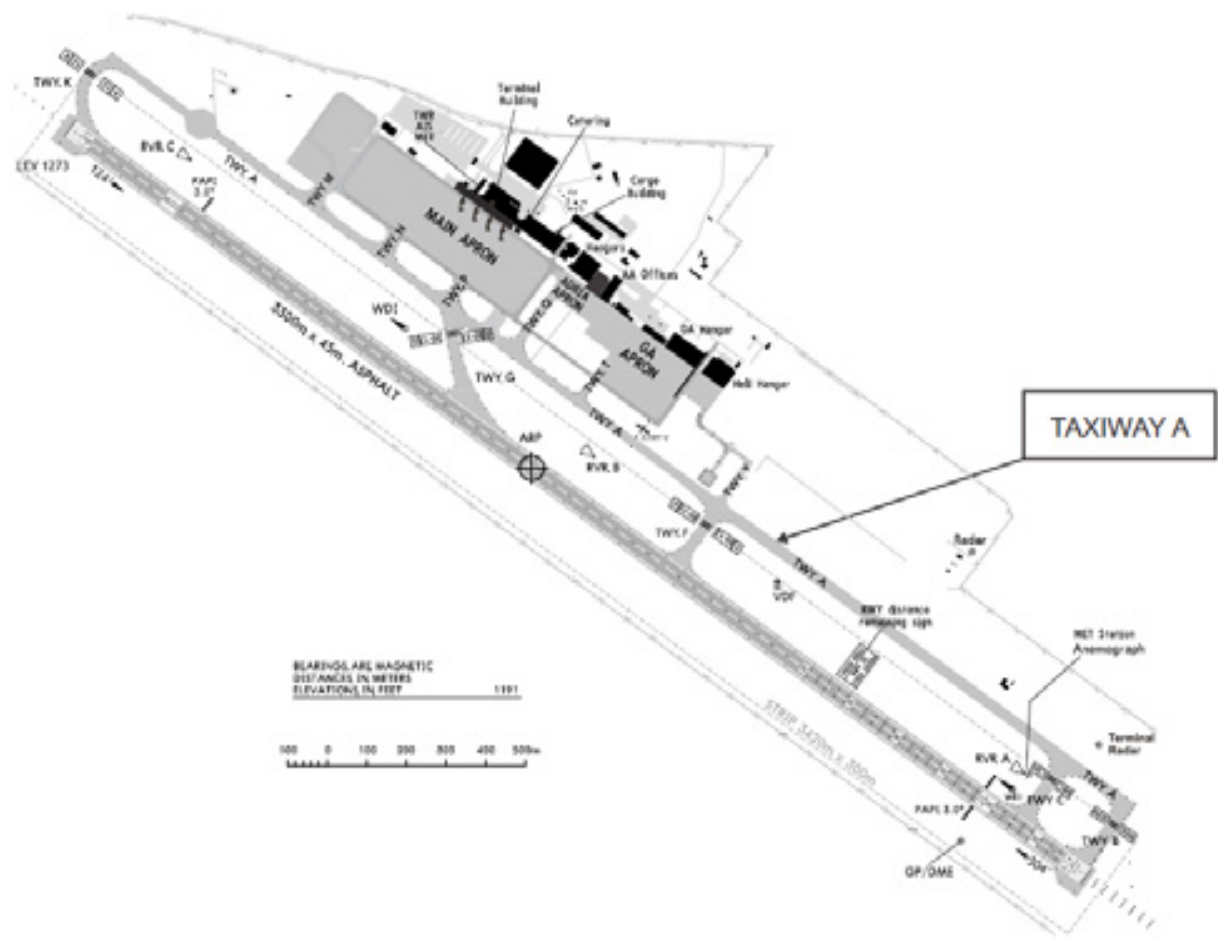

Fig. 2.

Airport Runway and Taxiways Layout at Present Source: Sloveniacontrol Ltd. (2014)

Traffic patterns did not change due to the fact that geographical obstacles, mainly the high terrain to the north and northwest dictate that all IFR climb-outs from the airport and descends towards the airport can only be performed on the south and southeastern side of the airport. IFR landings are still only possible on the runway 30 . Major contribution of the extended taxiway $\mathrm{A}$ is that aircraft category A do not need to execute backtrack on the runway in case of IFR departures from runway 30.

Simultaneously, mainly due to the overall increase in air navigation aids reliability and accuracy, final approach fix (FAF), the point at which the final approach for landing starts, was moved from 10,5 NM from the threshold of the runway 30 to $8,9 \mathrm{NM}$ from this very threshold. This somehow influences the calculated times in $\left[M_{i j}\right]$, which are now somewhat shorter.

\subsubsection{Capacity Calculation for Arrivals only on Runway 30}

Despite of the fact, that the arrival path is slightly shorter by $1,6 \mathrm{NM}$, this only marginally changes minimum inter-arrival times in the matrix $\left[M_{i j}\right]$.

Runway capacity for arrivals only $\left(C_{a}\right)$, still remains at 19 operations per hour. 


\subsubsection{Capacity Calculation for Departures only from Runway 30}

Due to the fact that aircraft category A now do not need to backtrack the runway anymore, the matrix of separation times $\left[t_{d}\right]$ in Table 2 can be modified as in 2.3.5:

\begin{tabular}{|c|c|c|c|}
\hline & & ailing & \\
\hline & $A$ & $B$ & \\
\hline & & & \\
\hline & \begin{tabular}{l|l}
$B$ & 240
\end{tabular} & 180 & 120 \\
\hline & $C[240$ & 180 & ]180 \\
\hline
\end{tabular}

With the help of data $\left[t_{d}\right]$ above and Eqs. (7) and (8), runway capacity for departures only runway $30\left(C_{d}\right)$, was calculated at 26 operations per hour.

\subsubsection{Capacity Calculation for Mixed Operations on Runway 30}

As in 2.3.3 $\boldsymbol{E}\left(\Delta \boldsymbol{T}_{i j}\right)$ was calculated using the Eq. (9). Data from Table 1 was used for calculation of $\boldsymbol{E}\left(\boldsymbol{R}_{\boldsymbol{i}}\right)$ as well as data from Tables 1 and 2 were used for calculation of $E\left(\frac{\delta_{d}}{v_{j}}\right)$

Finally data from $\boldsymbol{P}_{\boldsymbol{i} \boldsymbol{j}}$ and $\boldsymbol{B}_{\boldsymbol{i} \boldsymbol{j}}$ were used for calculation of $\boldsymbol{E}\left(\boldsymbol{B}_{\boldsymbol{i j}}\right)$. Results showed that $125 \mathrm{~s}$ is needed to release one departure between the two arrivals, $359 \mathrm{~s}$ is needed to release two departures between the two arrivals and $593 \mathrm{~s}$ is needed to release three departures between the two arrivals.
Since backtrack on the runway for category A aircraft is not necessary anymore, it can be concluded that $p_{n d}$ to release one departure between the two arrivals is 0,93 (93\%), to release two departures between the two arrivals is 0,07 (7\%) and to release three departures between the two arrivals is 0 .

With the help of Eq. (10) runway capacity for mixed operations $\left(C_{m}\right)$, was calculated at 32 operations per hour.

\subsubsection{Ultimate Capacity Calculation for Runway 30}

Traffic operations at Ljubljana - Jože Pučnik Airport remain relatively steady over the years, therefore it is still safe to assume that in one hour, one third of the time aircraft only depart, one third of the time aircraft only arrive and one third of the time mixed operations are performed.

Ultimate capacity $\left(C_{r}\right)$ was again calculated with the help of Eq. (11). Results show that the ultimate runway capacity for runway $30\left(C_{r}\right)$, was calculated at 26 operations per hour.

\subsubsection{Overview of Capacity Change}

For better visibility and possibility of instant comparison of the effect of taxiway A extension on the runway capacity, results are summed up in Table 3. 
Table 3

Overview of Capacity Change

\begin{tabular}{|l|c|c|}
\hline \multirow{2}{*}{ Sequence of operations and runway direction } & \multicolumn{2}{|c|}{ Runway capacity [operations/hour] } \\
\cline { 2 - 3 } & $\begin{array}{c}\text { Before taxiway A } \\
\text { extension }\end{array}$ & $\begin{array}{c}\text { After taxiway A } \\
\text { extension }\end{array}$ \\
\hline Arrivals only 31 (30) & 19 & 19 \\
\hline Departures only 31 (30) & 16 & 26 \\
\hline Mixed operations 31 (30) & 23 & 32 \\
\hline Ultimate capacity 31 (30) & 20 & 26 \\
\hline Departures only 13 (12) & 26 & 26 \\
\hline Mixed operations 31/13 (30/12) & 13 & 13 \\
\hline Ultimate capacity mixed operations 31/13 (30/12) & 20 & 20 \\
\hline
\end{tabular}

\section{Conclusion}

This study showed that only a slight change in an airport layout, if properly chosen, can significantly increase the runway capacity of an airport and therefore contribute to an overall productivity and cost effectiveness of an airport as well as of an air navigation services provider.

Extension of the taxiway A at Ljubljana Jože Pučnik Airport clearly contributed to almost $25 \%$ in increase of runway 30 capacity. Ultimate runway capacity based on the real time scenario type of operations increased from 20 to 26 operations per hour.

Omission of the backtrack for category A aircraft heavily influenced runway capacity for departures only, from 16 to 26 operations per hour (by almost 63\%) as well as runway capacity for mixed operations from 23 to 32 operations per hour (by almost $40 \%$ ).

On the other hand slight shortening of the arrival path by $1,6 \mathrm{NM}$, although at the first glimpse quite impressive, did not influence

the $\left[M_{i j}\right]$ to that extend that it would make any significant effect as well on the runway capacity calculations.
Current figures (Aerodrom Ljubljana, 2014) show that Ljubljana - Jože Pučnik Airport on average serves around 40 arrivals and equal number of departures per day. This is far below the saturation point of the airport, since the daily amount of arrivals and departures can theoretically be serviced in a couple of hours. Regardless of this fact, additional capacity, if required, can easily be obtained by lowering the separation minimum on the final approach from $5 \mathrm{NM}$ to $3 \mathrm{NM}$, through investment in additional/ more precise radio navigational aids, thus obtaining greater density of arrivals and by building additional rapid exit taxiways from runway 30 , thus enabling faster vacation of the runway 30 . However all this is bound to induce additional costs, which should be scrutinized through cost-benefit analysis and should at the end definitely pay off.

So far, just by a relatively, to the general public insignificant, although quite costly investment in extension of the taxiway A, Ljubljana - Jože Pučnik Airport made room for years of additional traffic growth, assuring as well satisfaction of the passengers and airport users. 


\section{References}

Aerodrom Ljubljana. 2014. Traffic figures. Available from Internet: <http://www.lju-airport.si/en/company/ traffic-figures/>.

EUROCONTROL. 2013. EUROCONTROL 2012 Annual Report. European Organization for the Safety of Air Navigation (EUROCONTROL), Brussels, July 2013.

Grebenšek, A.; Pavlin, S. 2004. Calculation of the runway capacity of Ljubljana - Brnik Airport, Promet - TrafficTraffico, 16(1): 21-26.

Horonjeff, R.; McKelvey, F.X.; Sproule, J.W.; Young, S.B. 2010. Planning and Design of Airports, fifth edition 2010, McGraw - Hill, Inc.

Kumar, V.; Sherry, L. 2009. Airport throughput capacity limits for demand management planning. Integrated Communications, Navigation and Surveillance Conference, 2009. ICNS '09, Arlington, VA, U.S.A.
Mota, M.M.; Boosten, G. 2013. Assessing the Impact of a Constrained Airport on the Capacity of an Airport Network with Simulation Techniques. INAIR 2013, Bratislava, Slovakia.

Šimecki, A.; Steiner, S.; Čokorilo, O. 2013. The Accessibility Assessment of Regional Transport Network in the South East Europe, International Journal For Traffic and Transport Engineering. DOI: http://dx.doi. org/10.7708/ijtte.2013.3(4).01, 3(4): 351-364.

Sloveniacontrol Ltd. 2014. e-AIP. Available from Internet: <http://www.sloveniacontrol.si/acrobat/ aip/Operations/2014-01-13/html/index.html>. 